\title{
The Role of Childhood Trauma in the Neurobiology of Mood and Anxiety Disorders: Preclinical and Clinical Studies
}

\author{
Christine Heim and Charles B. Nemeroff
}

Epidemiologic studies indicate that children exposed to early adverse experiences are at increased risk for the development of depression, anxiety disorders, or both. Persistent sensitization of central nervous system (CNS) circuits as a consequence of early life stress, which are integrally involved in the regulation of stress and emotion, may represent the underlying biological substrate of an increased vulnerability to subsequent stress as well as to the development of depression and anxiety. A number of preclinical studies suggest that early life stress induces long-lived hyper(re)activity of corticotropin-releasing factor (CRF) systems as well as alterations in other neurotransmitter systems, resulting in increased stress responsiveness. Many of the findings from these preclinical studies are comparable to findings in adult patients with mood and anxiety disorders. Emerging evidence from clinical studies suggests that exposure to early life stress is associated with neurobiological changes in children and adults, which may underlie the increased risk of psychopathology. Current research is focused on strategies to prevent or reverse the detrimental effects of early life stress on the CNS. The identification of the neurobiological substrates of early adverse experience is of paramount importance for the development of novel treatments for children, adolescents, and adults. Biol Psychiatry 2001;49:1023-1039 (C) 2001 Society of Biological Psychiatry

Key Words: Stress, development, animal, human, depression, anxiety

\section{Introduction}

$\mathrm{T}$ he past decades have witnessed an increasing societal awareness of the presence and high incidence of child maltreatment, which has now been pronounced a public health problem of epidemic dimensions (Margolin and

From the Department of Psychiatry and Behavioral Sciences, Emory University School of Medicine, Atlanta, Georgia.

Address reprint requests to Charles B. Nemeroff, MD, $\mathrm{PhD}$, Department of Psychiatry and Behavioral Sciences, Emory University School of Medicine, 1639 Pierce Drive, WMRB, Suite 4000, Atlanta, GA 30322.

Received December 5, 2000; revised March 13, 2001; accepted March 30, 2001.
Gordis 2000). According to the National Center of Child Abuse and Neglect, approximately 1.5 million verified cases of child maltreatment are reported annually in the United States; more than half of these cases represent instances of neglect, and about 700,000 cases are incidents of sexual, physical, or emotional abuse (Sedlack and Broadhurst 1996). In addition to child maltreatment, large numbers of children experience the loss of a parent (Agid et al 2000) or live with a mentally ill parent likely unable of providing continuous parental care (Goodman and Gotlib 1999). In view of estimates that $5 \%$ to $16 \%$ of women are sexually or physically abused during pregnancy (Cokkinides et al 1999; Goodwin et al 2000; Hedin and Janson 2000; McFarlane et al 1996), it can also be assumed that a significant number of children are exposed to prenatal stress.

Compelling evidence from a variety of studies suggests that early life stress constitutes a major risk factor for the development and persistence of mental disorders. Increased rates of major depression, posttraumatic stress disorder (PTSD), attention-deficit/hyperactivity disorder, and other behavioral disorders have been reported for maltreated children (e.g., Famularo et al 1992; Pelcovitz et al 1994). Representative of many other studies, a community-based study of almost 2000 adult women revealed that those with a history of childhood sexual or physical abuse, but not adulthood rape or physical assault, exhibited more symptoms of depression and anxiety and had more frequently attempted suicide than women without a history of childhood abuse (McCauley et al 1997). Syndromal major depression and anxiety disorders, including panic disorder and PTSD, are frequent in adults with a history of childhood abuse (e.g., Felitti et al 1998; Mullen et al 1996; Saunders et al 1992; Stein et al 1996). Similar findings have been reported for other instances of early life stress. For example, early parental loss has been found to be related to unipolar and bipolar depression, as well as anxiety disorders, beyond familial or genetic factors (Agid et al 1999; Kendler et al 1992, 1993). Moreover, prenatal stress has been related to an increased risk for major depression in adulthood (Hulshoff et al 2000). Early life 


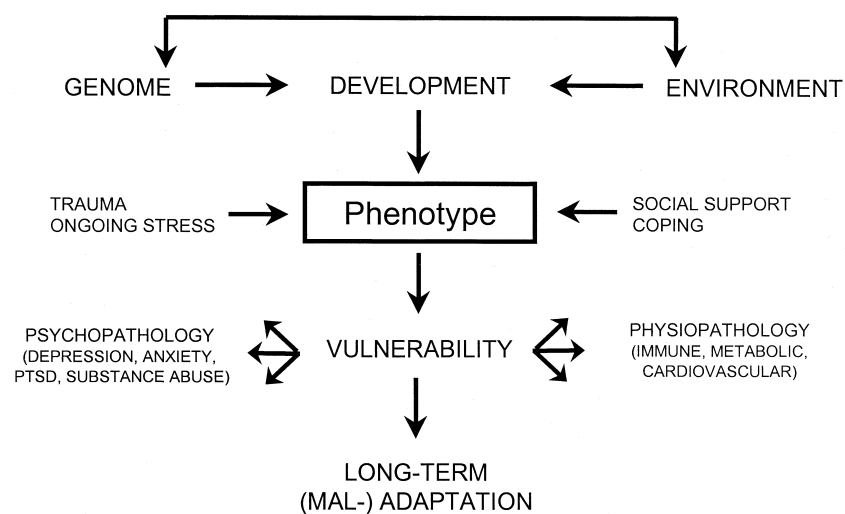

Figure 1. Proposed model of the interaction between genetic disposition and early environment leading to a vulnerable phenotype. Subsequent exposure to stress or trauma throughout the life span may induce exacerbation of pathology based on the underlying vulnerability. Social support or coping styles may buffer the effects of early life stress on vulnerability. Modified by Dr. P.M. Plotsky from Ladd et al (2000) with permission.

stress has also been associated with increased risk for other disorders, including schizophrenia and substance abuse (Agid et al 1999; Felitti et al 1998; Kendler et al 2000) as well as diabetes, heart disease, and immune disorders (Felitti et al 1998; Francis et al 1999; Wallace 1987). The manifestation or worsening of these psychiatric and classical medical disorders in adulthood is often related to acute life events or ongoing stress (Hammen et al 1992; Mooy et al 2000; Norman and Malla 1994; Twisk et al 1999). Thus, it may be suggested that adverse experience during development may induce a vulnerability to the effects of stress later in life, predisposing these individuals to develop a wide array mental and physical disorders that are known to manifest or worsen in relation to acute or chronic life stress.

Vulnerability to stress and disease is surely not the exclusive consequence of an adverse early environment, but is well documented to be influenced by genetic factors (see Francis et al 1999). Thus, the concatenation of genetics, early life stress, and ongoing stress may ultimately determine individual stress responsiveness and the manifestation of psychiatric disorders. Thus, an epidemiologic twin study indicated that the manifestation of major depression occurs as a function of genetic disposition, early trauma, and recent life stress (Kendler et al 1993). Early adverse experiences may "shape" a preexisting genetic vulnerability to stress and disease, resulting in a stable phenotype, with a certain risk to develop one or another syndrome in response to further stress exposure (see Figure 1). By what means can early adverse experiences shape a vulnerable phenotype? It is likely that early adverse experiences induce a persistent sensitization of stress-responsive neural circuits. There are a number of excellent recent reviews on the neurobiological consequences of early developmental stress in animals (Francis et al 1999; Kaufman et al 2000; Ladd et al 2000). This review seeks to provide an update of preclinical findings and summarizes available clinical data on the neurobiological consequences of early life stress in children and adults.

\section{Neural Circuits Implicated in Stress, Depression, and Anxiety}

The relationship between early life stress and the development of major depression and anxiety disorders, as well as other mental and physical disorders, may be hypothesized to be mediated by persistent changes in corticotropin-releasing factor (CRF) neurotransmission and alterations in other neurotransmitter systems implicated in the regulation of the stress responses (e.g., Nemeroff 1999). Because of its strategic distribution throughout the central nervous system (CNS), the 41 amino acid peptide, CRF, is generally acknowledged to be the major coordinator of the behavioral, autonomic, immune, and endocrine components of the mammalian stress response. The cell bodies in the medial parvocellular region of the hypothalamic paraventricular nucleus (PVN) containing CRF form the central component of the hypothalamic-pituitary-adrenal (HPA) axis, which constitutes the major neuroendocrine stress response system. Upon stress exposure, CRF is released from the median eminence nerve terminals into the hypothalamo-hypophysial portal circulation and transported to the anterior pituitary, where it binds to CRF receptors on the corticotropes, thereby stimulating the production and release of the proopiomelanocortin (POMC)-derivatives, adrenocorticotropin (ACTH) and $\beta$-endorphin. In turn, ACTH stimulates the synthesis and secretion of glucocorticoids from the adrenal cortex (see Arborelius et al 1999). Circulating glucocorticoids exert a wide range of metabolic and immune-modulating effects and counter-regulate the neuroendcorine stress response by negative feedback at pituitary, hypothalamic, and hippocampal levels. Negative feedback is mediated via two types of adrenal steroid receptors: the high-affinity mineralocorticoid receptors (MR) in the hippocampus and the low-affinity glucocorticoid receptors (GR) widely distributed throughout the brain. Although increased glucocorticoid secretion is critical to the adaptation of an organism to stress, prolonged or excessive exposure to glucocorticoids may be deleterious because of untoward effects on the CNS and physical organs (see McEwen 1998).

It is now well established that CRF, beyond its role as a hypothalamic hypophysiotropic hormone, also serves as a neurotransmitter within the CNS, mediating autonomic 
and behavioral stress responses. Thus, when administered directly into the CNS of laboratory animals, CRF produces effects that are reminiscent of stress, depression, and anxiety, including increases in peripheral catecholamine secretion, heart rate and arterial pressure, changes in gastrointestinal activity, decreased reproductive behavior, decreased appetite, disruption of sleep, increased grooming behavior, increased locomotor activity in a familiar environment, suppression of exploratory behavior in a novel environment, potentiation of acoustic startle responses, facilitation of fear conditioning, and enhancement of shock-induced freezing and fighting behavior (see Dunn and Berridge 1990; Owens and Nemeroff 1991). There is evidence that these effects are mediated via binding of $\mathrm{CRF}$ to $\mathrm{CRF}_{1}$ receptors, whereas $\mathrm{CRF}_{2}$ receptors that bind with high affinity to urocortin, a related endogenous neuropeptide, appear to be involved in dampening stress and fear (see Arborelius et al 1999).

The capability of CRF to integrate the mammalian organism's responses to stress is founded on widespread CRF neuronal circuitry connecting brain structures critical to cognitive and emotional processing with autonomic outflow centers and the hypothalamus. Thus, an abundant presence of CRF neurons and its receptors is found in the neocortex and the central nucleus of the amygdala, a key brain site in the mediation of emotions (see LeDoux 2000). The CRF neurons originating in the central nucleus of the amygdala project directly and indirectly, via the bed nucleus of the stria terminalis, to the hypothalamic PVN and likely influence pituitary-adrenal responses to stress. Thus, electrical stimulation of the central nucleus of the amygdala results in increased neuroendocrine stress responses, whereas lesion of the same region results in decreased responses (see Feldman and Weidenfeld 1995). The CRF neurons of the central nucleus of the amygdala are also directly and indirectly connected to brain-stem nuclei, including the locus coeruleus (LC) and the raphé nuclei. The LC regulates autonomic outflow and is the major source of the noradrenergic perikarya projecting to the forebrain. The raphé nuclei contain the bulk of the serotonergic projections to the forebrain. Noradrenergic and serotonergic neurons themselves send projections to various brain regions that contain CRF neurons or are otherwise involved in the stress response (see Owens and Nemeroff 1991). Consistent with these neuroanatomic connections, on a functional level, stress results in increases of CRF concentrations in the central nucleus of the amygdala as well as the LC (Chappell et al 1986; Pich et al 1993). Microinjection studies have shown that CRF induces many behaviors reminiscent of fear or anxiety through actions on specific brain regions (Butler et al 1990; Liang and Lee 1988; Weiss et al 1994). Moreover, it has been shown that CRF increases the firing rate of noradrenergic neurons in the LC (Valentino et al 1983), likely resulting in sympathetic nervous system activation and noradrenergic stimulation of CRF in the PVN. In contrast, CRF predominantly inhibits serotonergic neurons in the raphé nuclei (Kirby et al 2000; Price et al 1998), which modulate stress responses through projections to the PVN, amygdala, and the hippocampus. Increasing evidence suggests that $\gamma$-aminobutyric acid (GABA)-containing neurons located in these brain structures exert inhibitory influences on central CRF neurons and stress responsiveness (see Kaufman et al 2000). Another important structure involved in the regulation of emotion is the prefrontal cortex, which is believed to control behavioral and pituitary-adrenal responses to stress through inhibitory GABA-ergic projections to the amygdala and the hypothalamus (see Davidson et al 2000).

Taken together, there is a corpus of literature inferring a role for CRF as a key mediator of the stress response. Preclinical studies suggest that CRF possesses marked depressogenic properties and is involved in the mediation of fear and anxiety, consistent with its neuroanatomic distribution and its mutual interactions with other neurotransmitter circuits involved in the regulation of emotion.

\section{Preclinical Findings on the Neurobiological Consequences of Early Life Stress}

Given the preclinical evidence for a role of CRF in the mediation of stress and emotion, it may be plausible that early adversities induce persistent changes in CRF neural circuits that are associated with the development of depression or certain anxiety disorders. Preclinical studies using rodents or nonhuman primates are indispensable to improve our understanding of the consequences of early life stress because experimental variation of early environment in humans is obviously precluded on ethical grounds. Although a large number of studies have evaluated the long-term neurobiological adaptations to perturbations of the early environment in rodents or nonhuman primates, few preclinical studies exist on the immediate effects of early developmental stress on the brain.

Among animal models of early life stress in rodents is repeated separations of rat pups from their mothers during the neonatal period. Although there is evidence for a stress hyporesponsive period in neonatal rats, our group observed significant rises in plasma corticosterone levels both on postnatal day (pnd) 10 and pnd 18 in rats subjected to maternal deprivation. After 24 hours of maternal separation, we observed a reduction of CRF concentrations in the median eminence in 10-day-old rats and a 50\% reduction of pituitary CRF receptors in 18-day-old rats, likely reflecting sustained release of CRF (Pihoker et al 1993). Another study reported that 12-day-old rats ex- 
Table 1. Findings on the Long-Term Neurobiological Consequences of Early Environmental Variation in Selected Animal Models

\begin{tabular}{|c|c|c|c|c|}
\hline Model & Species & Timing & Neurobiological Changes & \\
\hline \multirow[t]{8}{*}{ Increased maternal caregiving behavior } & Rats & Observed at pnd $1-10$ & ACTH after stress & $\downarrow$ \\
\hline & & & CORT after stress & $\downarrow$ \\
\hline & & & CRF mRNA in PVN & $\downarrow$ \\
\hline & & & $\mathrm{CRF}$ receptor binding in $\mathrm{LC}$ & $\downarrow$ \\
\hline & & & $\alpha_{2}$ receptor binding in $\mathrm{LC}$ & $\uparrow$ \\
\hline & & & $\mathrm{CBZ}$ in $\mathrm{CeA}, \mathrm{LnA}, \mathrm{LC}$ & $\uparrow$ \\
\hline & & & GR mRNA in hippocampus & $\uparrow$ \\
\hline & & & Synaptogenesis in hippocampus & $\uparrow$ \\
\hline \multirow[t]{17}{*}{ Maternal separation } & Rats & $180 \mathrm{~min} /$ day pnd $2-14$ & ACTH after stress & $\uparrow$ \\
\hline & & & CORT after stress & $\uparrow$ \\
\hline & & & CRF in CSF, ME, LC & $\uparrow$ \\
\hline & & & $\mathrm{CRF}$ receptor binding in $\mathrm{LC}$ & $\uparrow$ \\
\hline & & & CRF mRNA in PVN, CeA, BNST & $\uparrow$ \\
\hline & & & NE in PVN & $\uparrow$ \\
\hline & & & $\mathrm{GABA}_{\mathrm{A}}$ receptor binding in $\mathrm{CeA}, \mathrm{BnA}, \mathrm{FC}$ & $\downarrow$ \\
\hline & & & $\mathrm{CBZ}$ in $\mathrm{CeA}, \mathrm{BnA}, \mathrm{LC}, \mathrm{NTS}$ & $\downarrow$ \\
\hline & & & GR in hippocampus & $\downarrow$ \\
\hline & & & 5-HT cell firing in NR after citalopram & $\downarrow$ \\
\hline & Rats & $4-6$ hour/day pnd $2-14$ & ACTH basal and after stress & $\uparrow$ \\
\hline & & & CORT basal and after stress & $\rightarrow$ \\
\hline & & & $\mathrm{CRF}$ in $\mathrm{ME}$ & $\uparrow$ \\
\hline & & & Pituitary CRF receptor binding in NR & $\downarrow$ \\
\hline & & & $\mathrm{CRF}$ receptor binding in $\mathrm{NR}$ & $\uparrow$ \\
\hline & Nonhuman primates & Separated after birth and & ACTH after stress & $\uparrow$ \\
\hline & & peer reared & CORT after stress & \\
\hline \multirow[t]{5}{*}{ Variable foraging demand } & Nonhuman primates & 12 weeks beginning at & CSF CRF & $\uparrow$ \\
\hline & & $\sim 17$ weeks of age & CSF CORT & $\downarrow$ \\
\hline & & & Behavioral response to yohimbine & $\uparrow$ \\
\hline & & & GH response to clonidine & $\downarrow$ \\
\hline & & & Behavioral response to $\mathrm{m}-\mathrm{CPP}$ & $\downarrow$ \\
\hline
\end{tabular}

$\mathrm{ACTH}=$ adrenocorticotropic hormone; $\mathrm{BNST}=$ bed nucleus of the stria terminalis; $\mathrm{CBZ}=$ central benzodiazepine receptor; CeA $=$ central nucleus of the amygdala $\mathrm{CORT}=$ corticosterone or cortisol; $\mathrm{CRF}=$ corticotropin-releasing factor; $\mathrm{CSF}=$ cerebrospinal fluid; $\mathrm{FC}=$ frontal cortex; $\mathrm{GABA} \mathrm{A}_{\mathrm{A}}=$ gamma-aminobutyric acid $\mathrm{A}$ receptor; $\mathrm{GH}=$ growth hormone; $\mathrm{GR}=$ glucocorticoid receptor; $\mathrm{LC}=$ locus coeruleus; $\mathrm{BnA}=$ basolateral nucleus of the amygdala; $\mathrm{m}-\mathrm{CPP}=$ meta-chlorophenylpiperazine; $\mathrm{ME}=$ median eminence; mRNA = messenger ribonucleic acid; NR = nucleus raphe; NTS = nucleus tractus solitarius; pnd $=$ postnatal day; PVN $=$ paraventricular nucleus.

posed to maternal deprivation exhibit increased ACTH responses to restraint stress compared with rats not exposed to maternal separation (Dent et al 2000). Although a rapid increase in CRFmRNA expression in the PVN was observed in both groups, only the maternally separated rats exhibited increased arginine vasopressin (AVP) mRNA expression, suggesting that increased stress responsiveness may be associated with the synergy of releasing effects of CRF and AVP. There is, furthermore, important evidence that there are critical developmental "windows," in which early life stress may have differential effects on neurobiological function. Thus, prolonged maternal separation over 24 hours at pnd 3-4 produces increased ACTH and normal corticosterone responses to stress at pnd 20 in rats, whereas prolonged maternal separation at pnd 11-12 produces blunted ACTH and normal corticosterone responses to stress at pnd 20 (van Oers et al 1998; Workel et al 1997). In a recent study, 6-month-old rhesus monkeys who were reared without their mothers but with peers showed increased cortisol responses to social separation compared with mother-reared rhesus monkeys, with cor- tisol increases predicting alcohol preference of these monkeys in young adulthood (Fahlke et al 2000). A magnetic resonance imaging (MRI) study found decreased volumes of the posterior corpus callosum, but not of the hippocampus, in prepubescent nonhuman primates reared under social isolation from 2 to 12 months of age compared with primates reared in a social environment (Sanchez et al 1998), paralleling findings in maltreated children (De Bellis et al 1999b, see below). Taken together, these findings suggest that intense neonatal stress induces immediate neurobiological changes, likely resulting in long-term maladaptations. More developmentally focused preclinical studies on the neurobiological impact of early life stress are strongly needed to elucidate the mechanisms of early-onset depression and other mental disorders after early life stress.

As for the long-term consequences of early life stress (see Table 1), adult rats separated from their dams for 180 min per day on pnd 2-14 demonstrate increased CRF concentrations in the median eminence, portal blood, and CSF, as well as increased CRF mRNA expression in the 
hypothalamic PVN and decreased pituitary CRF receptor binding under resting conditions compared with rats reared under normal animal facility conditions. Rats separated from their dams for 180 min per day on pnd 2-14 also exhibited increased ACTH and corticosterone responses to a variety of stressors, including the exposure to air-puff startle, novel environment, or restraint stress (Ladd et al 2000; Plotsky and Meaney 1993). Adult rats that were removed from their dams for 4-6 hours per day on pnd 2-21 also exhibited increased ACTH but notably normal corticosterone responses to foot-shock (Ladd et al 1996), suggesting that more severe or extended postnatal stress may promote adrenal dysfunction, which is also observed in other models of early life stress (Coplan et al 1996, see below).

Rats exposed to maternal separation for $180 \mathrm{~min}$ per day on pnd 2-14 also develop marked behavioral abnormalities, including reduced consumption of a sweetened solution reflecting anhedonia, as well as increased freezing in an open-field, decreased exploration of a novel environment, and increased acoustic startle responses, all indicative of fear (Caldji et al 2000; Ladd et al 2000). As outlined above, the underlying substrate of these behaviors may be increased CRF neurotransmission in corticolimbic and brain-stem circuits. Accordingly, adult rats that were separated from their dams in the same model demonstrate increased CRF mRNA expression in the central nucleus of the amygdala and in the bed nucleus of the stria terminalis. Moreover, discordant with the well-accepted concept of ligand-induced receptor regulation, increased CRF concentrations along with increased CRF receptor binding density was measured in the LC (Plotsky et al, in press). Consistent with the evidence that the LC-noradrenergic neurons project to the hypothalamus, increased concentrations of norepinephrine (NE) have been measured in the PVN of the hypothalamus of maternally separated rats (Liu et al 2000a). Norepinephrine serves as major stimulus for CRH release in the hypothalamus, suggesting that increased CRF transmission in pathways connecting the amygdala with the hypothalamus and the LC may contribute to enhanced neuroendocrine stress reactivity after early life stress.

With respect to other neurotransmitter systems, increased CRF receptor binding has been measured in the nuclei raphé (Ladd et al 1996). Corticotrophin releasing factor neurotransmission in the nuclei raphé is associated with predominantly decreased firing rates of serotonergic neurons (Kirby et al 2000; Price et al 1998). Indeed, adult rats separated from their dams for $180 \mathrm{~min}$ per day on pnd 2-14 exhibit decreases in serotonin (5-hydroxytryptamine [5-HT]) cell firing in the raphé nuclei in response to increasing doses of the selective 5-HT reuptake inhibitor citalopram, suggesting persistent alterations in 5-HT trans- porter, 5-HT1A autoreceptors, or both after maternal separation (Arborelius et al 2000). As noted before, serotonergic neurons originating in the raphé nuclei project to various brain regions that are pivotal to the control of the stress response, including the hippocampus and the prefrontal cortex. Serotonergic dysfunction may thus contribute to exaggerated neuroendocrine stress responsiveness after early life stress. In addition, it has previously been shown that maternal separation is associated with a decrease in hippocampal GR, reflecting impaired feedback inhibition of the HPA axis. Changes in hippocampal GR as a consequence of early environmental changes have been reported to be dependent on 5-HT (see Meaney et al 2000).

Several brain regions involved in the control or inhibition of the stress response send inhibitory GABA-ergic projections to various other brain regions involved in the stress response. A recent study has evaluated $\mathrm{GABA}_{\mathrm{A}}$ and central benzodiazepine receptor (CBZ) levels in the brain of maternally separated rats (Caldji et al 2000). Central benzodiazepine receptors are a component of the $\mathrm{GABA}_{\mathrm{A}}$ receptor and enhance the affinity of the $\mathrm{GABA}_{\mathrm{A}}$ receptor for GABA resulting in increased inhibition of fear and anxiety. For example, the anxiolytic actions of benzodiazepines are mediated by binding to the CBZ. Interestingly, it was found that maternally separated rats exhibit a decreased density of $\mathrm{GABA}_{\mathrm{A}}$ or CBZ binding sites in various brain regions, including the $\mathrm{LC}$, several nuclei of the amygdala, and the frontal cortex. It may thus be assumed that dysfunction of GABA-ergic neurotransmitter systems may contribute to enhanced stress responsiveness after early life stress.

Opposite to the long-term consequences of prolonged maternal separation, brief handling involving removal of rat pups from their dams for 15 min per day on pnd 2-14 results in a phenotype, which is less sensitive to stress, less fearful and thus better adapted compared with rats who were left undisturbed during the postnatal period (Francis et al 1999; Kaufman et al 2000; Plotsky and Meaney 1993). Pivotal to the understanding of the determinants involved in the mediation of the neurobiological consequences of early life stress in rodents are a series of findings showing that separation of rat pups from their dams results in alterations in maternal behavior. Compared with normal animal facility conditions, removal of pups from dams for $15 \mathrm{~min} /$ day has been shown to induce increased maternal care-giving behavior, as evidenced by increased licking, grooming, and arched-back nursing. Several studies have assessed the neurobiological and behavioral adaptations to naturally occurring variations in maternal behavior, without actually removing the pups from their dams (Caldji et al 1998; Liu et al 1997, 2000b). Remarkably, these studies showed that increased licking, 
grooming, and arched-back nursing behavior is highly correlated with decreased pituitary-adrenal responses to stress, increased GR binding and enhanced synaptogenesis in the hippocampus, decreased CRF mRNA expression in the hypothalamus along with decreased CRF receptor and increased presynaptic $\alpha_{2}$ receptor site binding, as well as increased CBZ receptors in the amygdala and LC. These rats were also less fearful when behaviorally tested (Caldji et al 1998; Liu et al 1997). The causal role of variations in maternal caregiving behavior in shaping a phenotype more or less vulnerable to stress has impressively been proven in a series of cross-fostering studies demonstrating that maternal behavior determines stress reactivity in the offspring and, moreover, that individual differences in maternal behavior are passed on the next generation through nongenomic transmission (Francis et al 1999). These findings are of paramount importance for our understanding of the long-term consequences of adverse parenting behavior in humans, such as child abuse or neglect, and its transition across generations. Interesting in this regard are findings suggesting that the neurobiological systems that are modified by early experience are also involved in the mediation of aggressive and abusive behavior (Davidson et al 2000).

Similar to findings in rodents, adult nonhuman primates that have been maternally deprived during infancy exhibit increased pituitary-adrenal and behavioral responses to acute stress, as well as signs of behavioral despair (Suomi 1991). Some studies on the long-term consequences of early life stress in nonhuman primates have also focused on variations in maternal behavior during infancy. In one model, mothers of infant bonnet macaques are exposed to different foraging demands over 12 weeks. Mothers with constantly low foraging demand (LFD) can obtain food without any effort, whereas mothers with constantly high foraging demand (HFD) have to complete a daily task to obtain their food. In a variable foraging demand (VFD) condition, mothers are exposed to unpredictable conditions with respect to food access, resulting in diminished perception of security and a reduction of maternal care in the infants. As adults, VFD-reared nonhuman primates exhibit stable traits of anxiety as well as significantly elevated CSF CRF concentrations when compared with LFD- or HFD-reared primates (Coplan et al 1996). There also appears to exist an opposite dysregulation of increased CRF and decreased adrenal activity. Nonhuman VFD-reared primates further exhibit exaggerated behavioral responses to the administration of the selective $\alpha_{2}$-receptor antagonist, yohimbine, and reduced growth hormone responses to the $\alpha_{2}$ agonist, clonidine, suggesting sensitization of the noradrenergic system as a consequence of early life stress (Coplan et al 2000; Rosenblum et al 1994). In addition, VFD-reared nonhuman primates ex- hibit decreased behavioral responsiveness to the 5-HT agonist meta-chlorophenylpiperazine (m-CPP), suggesting a dysfunctional 5-HT system after early life stress (Rosenblum et al 1994).

Importantly, increasing evidence from preclinical studies suggests that environmental influences may shape stress vulnerability of the offspring even in the prenatal period. Thus, adult rats exposed to prenatal stress show marked increases in fear-related behaviors (Takahashi et al 1992), along with increased ACTH responses to stress and decreased hippocampal GR levels as well as increases of CRF content and CRF receptor binding in the amygdala (see Cratty et al 1995; Maccari et al 1995; Ward et al 2000). Similar changes have been observed after prenatal alcohol exposure (Ogilvie and Rivier 1997). Some of these changes may be altered by postnatal maternal caregiving. In view of the relative high prevalence of prenatal stress in humans and its relationship to adult psychopathology, this area of investigation deserves further attention.

Taken together, there is considerable evidence from preclinical studies suggesting that an adverse early environment is associated with marked behavioral changes indicative of fear and anxiety, as well as with persistent alterations in CRF neural circuits, which may contribute to increased vulnerability for the development of depression or certain anxiety disorders.

\section{Comparison of Preclinical Findings on the Neurobiological Consequences of Early Life Stress with the Neurobiology of Mood and Anxiety Disorders}

The accumulating evidence from preclinical studies on early life stress suggesting persistent changes in brain regions pivotal to the mediation of stress and emotion has raised the question of whether patients suffering from depression or anxiety disorders exhibit similar neurobiological alterations.

Although many of the long-term consequences of early life stress in animals bear significant similarities with the neurobiological changes observed in adult patients with depression and some anxiety disorders, preclinical studies on the consequences of early life stress appear to be a poor heuristic for the neurobiology of child or adolescent affective disorders. For example, disturbances of the HPA axis, such as hypercortisolemia or blunted ACTH responses to CRF stimulation or other indices of HPA axis hyperactivity, are rare in depressed children, contrasting findings in adult major depression (Birmaher et al 1996; Dorn et al 1996; Kaufman and Ryan 1999). It may be argued that peripheral measures of pituitary-adrenal activity may not reflect central CRF activity at extrahypothalamic sites and, moreover, that peripheral changes may 
only develop over time with chronic or repeated depression (Martin et al 2000). Differential pathophysiology of depression at different developmental stages is further reflected by differences in responses to pharmacologic treatments in patients of different ages (Martin et al 2000); however, there is evidence that $\mathrm{CRH}$ and serotonergic alterations are present in depressed children with histories of maltreatment, but not in depressed nonabused children (Kaufman et al 1997, 1998; see next section), suggesting that preclinical studies on early life stress represent a heuristic specifically for understanding depression associated with early trauma. This subtype of depression may also more frequently occur in comorbidity with anxiety disorders. Some studies on the neurobiology of anxiety disorders in children and adolescents have yielded findings similar to some findings on the effects of early life stress in animals. For example, elevated ACTH but normal cortisol levels have been reported for children with generalized anxiety disorder who anticipated a laboratory stress task (Gerra et al 2000). Altered behavioral and hormonal responses to central noradrenergic stimulation have been observed in children with several anxiety disorders (Sallee et al 2000). Neurobiological alterations are also present in children with PTSD related to early trauma (see next section). It may be that early life stress affects neurobiological function in children with other anxiety disorders as well, similar to findings in early-onset depression.

As for studies in adults, increased CSF CRF-like immunoreactivity has been measured in untreated patients with depression, PTSD, and obsessive-compulsive disorder (OCD), but not panic disorder (see Heim and Nemeroff 1999). Importantly, two recent studies using serial CSF sampling techniques have provided evidence for sustained increases in CRF activation in both major depression and PTSD suggesting that CRF hypersecretion occurs independent of anxiety or stress related to the lumbar puncture (Baker et al 1999; Wong et al 2000). Concentrations of $\mathrm{CRF}$ in CSF are derived from various brain regions. Thus, these findings are consistent with findings of increased CRF activity in corticolimbic structures of animals exposed to early life stress. In addition, increased CRF and CRF mRNA levels have been measured in hypothalamic tissue obtained postmortem from depressed patients (Raadsheer et al 1994, 1995). Blunted ACTH responses to CRF injection have been reported for patients with depression, PTSD, and panic disorder, although increased responses to CRF also have been reported for panic disorder (see Heim and Nemeroff 1999). It may be that initial sensitization evolves into blunted responses reflecting, in part, down-regulation of pituitary CRF receptors as a consequence of hypothalamic CRF hypersecretion. These findings therefore parallel the findings indicative of in- creased hypothalamic CRF expression and release, as well as reductions in pituitary CRF receptors in maternally deprived rodents.

Although major depression and some anxiety disorders, including PTSD, panic disorder, and OCD, appear relatively similar with respect to central or hypothalamic CRF hypersecretion, findings at peripheral levels of the HPA axis are discordant. Melancholic major depression and OCD have been associated with hypercortisolism in some studies, whereas panic disorder (in the absence of comorbid depression) has been associated with normal basal cortisol secretion (see Heim and Nemeroff 1999). In contrast, adult patients with PTSD were shown to exhibit decreased adrenocortical activity in a series of studies (see Yehuda 2000), although this finding was not replicated in several other studies in adult PTSD patients (Lemieux and Coe 1995; Maes et al 1998). It has been suggested that decreased cortisol secretion found in some PTSD patients may reflect enhanced negative feedback inhibition of the HPA axis; however alterations at the adrenal level may, in part, contribute to altered cortisol concentrations. The opposite dysregulation of central and peripheral components of the stress system in PTSD parallels findings in some animal models of early life stress.

Consistent with feed-forward actions between central CRF and NE systems, recent evidence suggests sustained increases in CSF NE concentrations of depressed patients (Wong et al 2000). Pharmacologic provocation studies and peripheral catecholamine measures also suggest increased noradrenergic activity in several anxiety disorders, including PTSD and panic disorder (see Coplan et al 1996). In addition, indices of serotonergic dysfunction have been reported for patients with depression, PTSD, OCD, and social phobia (Hollander et al 1998; Newport and Nemeroff 2000; Owens and Nemeroff 1994; Stein et al 1999). Regarding GABA-ergic systems, recent functional neuroimaging studies revealed decreased cortical GABA concentrations in depressed patients, as well as decreased prefrontal CBZ receptors in patients with PTSD or panic disorder (Bremner et al 2000a, 2000b; Sanacora et al 1999). These findings parallel findings of noradrenergic, serotonergic, and GABA-ergic changes in animal models of early life stress.

Evidence from neuroimaging studies suggests morphologic and functional changes in brain structures involved in the control of the stress response in depression and some anxiety disorders. Thus, a reduction in hippocampal volume has been documented in several studies in adult patients with depression or PTSD (e.g., Bremner et al 1995, 2000c; Sheline et al 1996), although reduced hippocampal volume was not observed in childhood PTSD (De Bellis et al 1999b; see below). Reduced hippocampal volume may be a long-term consequence of overexposure 
to excitatory amino acids or glucocorticoids, potentially leading to cell atrophy, loss, or decreased neurogenesis (see Duman and Charney 1999). Potential mechanisms explaining the reductions in hippocampal size in potentially hypocortisolemic PTSD patients may include the cumulative effects of excessive adrenocortical responses to repeated stress in these patients or increased glucocorticoid sensitivity of the target cells. Neuroimaging studies have further documented alterations in the structure or activity patterns of the prefrontal cortex, which is involved in the inhibition of the stress response, in patients with depression or PTSD (Drevets 1999; Mayberg et al 1999; Newport and Nemeroff 2000; Rajkowska et al 1999). Structural alterations of the amygdala also have been noted in depression (Sheline et al 1998).

Although these findings provide evidence for increased activation of the central stress response system closely resembling findings in animal models of early life stress, a recent study reported reduced $\beta$-endorphin and normal cortisol responses to psychosocial laboratory stress in depressed patients (Young et al 2000). Although the authors argue that the blunted response may reflect increased feedback inhibition at the pituitary level given high basal cortisol levels in these patients, these findings are in contrast to findings in animal models of early life stress.

\section{Does Early Life Stress Induce Similar Neurobiological Alterations in Humans?}

Given the rapidly increasing number of preclinical studies on the consequences of early life stress and overwhelming evidence of a close relationship between early life stress and affective or anxiety disorders, a number of studies have evaluated neuroendocrine, neurochemical, and neurostructural-functional changes in children or adults with histories of early adversities.

\section{Studies in Children}

Several studies recruiting children of different ages who experienced different types of early life stress at different developmental stages report decreased salivary cortisol concentrations in the morning or a lack of decline of cortisol toward the evening, suggesting a disturbed circadian rhythm of the HPA axis (Carlson and Earls 1997; Goenjian et al 1996; Hart et al 1996; Kaufman 1991). Cortisol concentrations were related to symptoms of depression or PTSD. The absent decline of cortisol in these children may be due to higher numbers of stressful events during the day or increased HPA responses to daily stress. Thus, unlike findings in Vietnam veterans with PTSD, the total 24-hour urinary cortisol excretion is unaltered or increased in maltreated children, depending on the duration of the abuse and the severity of psychopathology (De Bellis et al 1994, 1999a).

In response to a CRF stimulation test, sexually abused girls demonstrated a markedly blunted ACTH response compared with control subjects in one study (De Bellis et al 1994), reflecting in part pituitary CRF receptor downregulation due to hypothalamic CRF hypersecretion. Another study using the CRF stimulation test found enhanced ACTH and normal cortisol responses in abused children with current depression compared to nonabused depressed children and control subjects (Kaufman et al 1997). About half of these children were emotionally abused at the time of the study. In a naturalistic stress study, maltreated children did not show an increase of cortisol in a social conflict situation, whereas control subjects showed increases (Hart et al 1995), but these results may reflect lack of novelty to such situations in maltreated children, rather than decreased stress sensitivity. Two studies using the dexamethasone suppression test in children with acute parental death (Weller et al 1990) and children who were in an earthquake 5 years before the study (Goenjian et al 1996) yielded opposite results. Although bereaved children were depressed and did not adequately suppress cortisol, the children exposed to the earthquake showed symptoms of PTSD and enhanced suppression of cortisol, similar to some findings in adult patients with PTSD. Taken together, it is evident that neuroendocrine dysfunction in children with early life stress is highly variable and likely influenced by multiple factors (i.e., type, age at onset and duration of the stressful event, the time elapsed since the event, concomitant stress and psychopathology). Moreover, a stable phenotype of altered stress vulnerability related to early life stress may not yet have evolved in children.

Similar to findings in animal models of early stress and adult patients with depression or PTSD, elevated 24-hour urinary NE, epinephrine (E), and dopamine (DA) excretion as well as decreased platelet adrenergic receptors have been measured in abused children with PTSD (De Bellis et al 1999a; Perry 1994). Abused children with PTSD also exhibit increased heart rate and blood pressure levels at rest and after orthostatic challenge (Perry 1994). Elevated catecholamine secretion does not appear to be an exclusive correlate of psychopathology because elevated levels were also found in abused girls without PTSD (De Bellis et al 1997) and children whose parents had marital problems (Gottman and Katz 1989). Notably, decreased levels of $\mathrm{NE}$ and DA- $\beta$-hydroxylase $(\mathrm{D} \beta \mathrm{H})$, the rate limiting factor in the synthesis of NE, were observed in children who were neglected in infancy (see Rogeness and McClure 1996), indicating that the type and timing of early stress 
may determine the direction of biological changes, which may be related to differential psychopathology.

Indicative of serotonergic dysfunction, abused children with depression were shown to exhibit increased prolactin but normal cortisol responses to the injection of L-5hydroxytryptophan, a precursor of 5-HT, compared with nonabused depressed children and control subjects (Kaufman et al 1998). Likewise, increased prolactin responses to fenfluramine were observed in boys with adverse rearing environment (Pine et al 1997). Since prolactin but not cortisol release is mediated via $5-\mathrm{HT}_{1 \mathrm{~A}}$ receptors, these findings suggest sensitization of these receptors due to early life stress. Another study recently reported that children with traumatic brain injury (TBI) who had experienced abuse have dramatic increases in CSF concentrations of glutamate compared with nonabused TBI children (Ruppel et al 2001). Consistent with a role of glutamate in the phenomenon of excitotoxicity during neural injury, increased glutamate concentrations were related to poor outcome in these children.

In contrast to findings in adult depression and PTSD, normal hippocampal volumes were observed in maltreated children with PTSD (De Bellis et al 1999b; also see below); however, similar to findings in prepubescent primates exposed to early stress (Sanchez et al 1998), these children exhibited decreased volumes of the corpus callosum. Furthermore, a proton magnetic resonance spectroscopy study found smaller ratios of $\mathrm{N}$-acetylasparate to creatine in the anterior cingulate of abused children with PTSD compared with control subjects (De Bellis et al 2000), which is thought to reflect decreased neural integrity in this brain region.

\section{Studies in Adults}

A limited number of retrospective studies have evaluated the long-term consequences of early life stress in adults. Lemieux and Coe (1995) observed increased 24-hour urinary cortisol excretion in women with a history of childhood sexual abuse and PTSD, concordant to findings in abused children with PTSD. These findings are opposite to findings in Vietnam veterans and Holocaust survivors with PTSD (Yehuda 2000). Increased plasma cortisol concentrations were also measured in adults who experienced the death of a parent in childhood and had obtained a lifetime psychiatric diagnosis (Breier et al 1988). Cortisol suppression after dexamethasone was normal in these subjects. In another study, women with a history of childhood sexual abuse were found to show hypersuppression of salivary cortisol concentrations in response to a low dose of dexamethasone (Stein et al 1997a). Basal morning cortisol concentrations and GR binding were unaltered in these women; however, there was a trend for higher GR binding in abused women with PTSD or dissociation. We found decreased basal plasma cortisol concentrations in the morning in abused women (Heim et al, 2001). The variance in these data may in part reflect methodologic differences. It may be that increased 24-hour urinary cortisol excretion in part reflects enhanced fluctuation of cortisol release in response to stress throughout the day in abused women with PTSD.

Given the clear preclinical evidence for long-term sensitization of the stress response after early life stress, it is important to evaluate neuroendocrine stress responsiveness in adult humans exposed to early life stress. We found that abused women with or without current depression exhibit markedly increased plasma ACTH responses to psychosocial laboratory stress compared with control subjects and depressed women without early life stress (Heim et al 2000). Abused women with depression also exhibited increased cortisol responses to stress compared with all other groups. Similarly, an increase of cortisol during a speech in front of a video camera was noted in adults with parental loss experience, whereas cortisol levels decreased in control subjects (Luecken 1998). These findings are remarkably consistent with findings from animal studies suggesting sensitization of the neuroendocrine stress responses after early life stress in humans, which may in turn be related to an increased risk for psychopathology. Similar to findings in depressed children, our findings suggest that there are subgroups of depression with differential pathophysiology depending on early trauma, explaining the inconsistency of findings in the literature, for example, Young et al (2000).

To further explore the mechanism(s) of pituitary-adrenal dysfunction in these women, we used a standard CRF stimulation test, which selectively stimulates pituitary CRF receptors without involving higher levels of HPA axis control (Heim et al 2001). Abused women without depression, similar to their responses in the social stress test, exhibited increased ACTH, but normal cortisol responses to oCRF. In contrast and opposed to their responses in the social stress test, abused women with depression exhibited a blunted ACTH response to exogenous CRF. This finding compares with classical findings in depression and was also observed in depressed women without abuse. Abused women with depression women also reported elevated levels of recent life stress. One may thus assume that early life stress is related to sensitization of the CRF neuronal circuits, resulting in high CRF secretion whenever these women are stressed. At the pituitary, this eventually leads to CRF receptor downregulation, and, because of CRF actions at extrahypothalamic sites, to signs and symptoms of depression and 
anxiety. The discrepancy between the responses in the stress test compared with the CRF stimulation test in abused women with depression remains unexplained but may involve activation of corticolimbic pathways. We further reported that abused women without depression release less cortisol during a standard $\mathrm{ACTH}_{1-24}$ stimulation test $(250 \mu \mathrm{g})$ (Heim et al 2001), suggesting peripheral adaptation to CNS hyperactivity, which parallels findings in animal models of early life stress and abused children with depression.

Parallel to findings in abused children with PTSD, elevated 24-hour urinary NE excretion was reported in abused women with PTSD (Lemieux and Coe 1995). In addition, increased heart rate or blood pressure responses have been observed during stress induction in adults with early parental loss and abused women with depression (Heim et al 2000; Luecken 1998) as well during mental imagery of abuse experiences in abused women with PTSD (Orr et al 1998), suggesting increased autonomic reactivity. With respect to serotonergic function, a history of severe childhood abuse was found to be highly correlated with blunted prolactin responses to m-CPP in adult women who suffered from borderline personality disorder (Rinne et al 2000). Because this finding is opposite to findings in maltreated children but comparable with findings in VFD-reared adult nonhuman primates, these authors suggested that the 5-HT system may undergo a developmental "switch" after early stress.

Similar to findings in adult depression or combatrelated PTSD, decreased hippocampal volumes have been measured in adults with perinatal trauma and adult women with child abuse and PTSD (Bremner et al 1997; McNeil et al 2000; Stein et al 1997b). Because hippocampal atrophy is not observed in abused children with PTSD (De Bellis et al 1999b), it may be hypothesized that repeatedly increased cortisol secretion over the course of time induces hippocampal cell loss and impaired neurogenesis in the dentate gyrus, which may further disinhibit cortisol secretion, eventually resulting in measurably smaller hippocampi. Two positron emission tomography studies reported decreased activation of the anterior cingulate during script-driven guided mental imagery of personal abuse experiences in abused women with PTSD relative to abused women without PTSD (see Newport and Nemeroff 2000), a structure that is also abnormally developed in maltreated children with PTSD. These studies also found altered activation of several areas of the frontal cortex, which are involved in the processing of emotion; however, because of the immanent difficulties in including nonabused control subjects when reading trauma scripts, it cannot be decided whether early life stress per se is associated with these neurobiological changes.

\section{Are the Neurobiological Consequences of Early Life Stress Reversible?}

As we have shown, accumulating evidence from preclinical and clinical studies suggests that early life stress induces persistent sensitization of CRF neurocircuits, resulting in a phenotype with increased vulnerability to stress, depression, and anxiety. Pharmacologic agents that target central CRF systems may reverse the neurobiological consequences of early life stress and may therefore be useful in the prevention and treatment of disorders related to early life stress in children and adults.

A number of studies provide evidence that different classes of antidepressants decrease CRF neuronal or HPA axis activity in rodents and primates, including humans (Bánki et al 1992; Brady et al 1991, 1992; De Bellis et al 1993; Michelson et al 1997; Veith et al 1993). It would appear that a decrease in the activity of one or more CRF neural systems is one shared mechanism of action of several classes of antidepressant drugs and may be relevant to their therapeutic efficacy. Many of the above effects were produced by drugs that affect the central serotonergic neurons, including the selective 5-HT reuptake inhibitors (SSRI). The SSRIs have been shown to be effective in the treatment of several psychiatric disorders that have been associated with early life stress (e.g., depression and PTSD; Hidalgo and Davidson 2000). Notably, in a randomized placebo-controlled trial, survivors of childhood abuse with PTSD were more responsive to fluoxetine than combat veterans with PTSD (van der Kolk et al 1994). Furthermore, SSRIs, including fluoxetine and paroxetine, show significant efficacy versus placebo in the treatment of early-onset depression in children and adolescents, whereas it appears to be resistant to tricyclic antidepressants (Martin et al 2000). Other SSRIs, such as sertraline or fluvoxamine, showed efficacy in open clinical trials in early-onset depression (Martin et al 2000). Interesting in this regard are findings showing that treatment of maternally deprived rats as adults with the selective 5-HT reuptake inhibitor paroxetine reverses the neurobiological consequences of early life stress, resulting in unaltered vulnerability to stress, depression, and anxiety (Plotsky et al in press). Tricyclic antidepressants have also been found to reverse increased HPA axis reactivity to stress in adult primates exposed to maternal deprivation (Suomi 1991). It appears that several available drugs, but namely the SSRIs, may be beneficial in the treatment of children and adults exposed to early life stress. Future preclinical studies will have to evaluate the efficacy of these drugs in the prevention or reversal of the effects of early life stress during development. Furthermore, the efficacy of other classes of available drugs known to decrease CRF activity, including the 5-HT/NE reuptake inhibitor venlafaxine and 
benzodiazepines (Owens et al 1996; Skelton et al 2000), in the prevention or reversal of the effects of early life stress should be studied. Clinical trials evaluating the efficacy of these available drugs in reversing neurobiological and psychological maladaptation in children and adults with histories of early life stress are urgently needed.

There are also promising novel drugs that may be efficient in the treatment of disorders related to early life stress. Thus, considerable attention has been directed toward the development and evaluation of CRF receptor antagonists. Given the integral role of CRF and its receptors in the mediation of stress and emotion, the $\mathrm{CRF}_{1}$ receptor antagonists are being discussed as novel antidepressants and anxiolytics as well as potentially preventive treatments for PTSD (Martin et al 2000). Oral administration of the $\mathrm{CRF}_{1}$ receptor antagonist antalarmin significantly decreased CSF CRF, pituitary-adrenal and autonomic responses to stress and inhibited behaviors indicative of fear and anxiety in adult primates (Habib et al 2000). The antidepressant and anxiolytic properties of the selective $\mathrm{CRF}_{1}$ receptor antagonist R121919 was recently demonstrated in a clinical trial of depressed patients (Zobel et al 2000). Interestingly, treatment of rats exposed to prenatal stress with CRF antagonists reverses the characteristic increases of fearful behavior observed in these animals (Ward et al 2000). In 9- to 11-day-old rat pups, the $\mathrm{CRF}_{1}$ receptor antagonist $\mathrm{CP} 154,526$ diminishes vocalizations indicative of anxiety in response to separation from their litters (Kehne et al 2000). Given the fact that early life stress is related to substantial alterations in central CRF systems, it is plausible that $\mathrm{CRF}_{1}$ receptor antagonists, once they are available, will represent the most direct treatment of symptoms related to early life stress in children and adults.

Finally, the intriguing evidence that the neurobiological effects of handling and maternal separation may be reversed by cross-fostering of the pups gives rise to the hypothesis that improvement of parental or foster care may help prevent or reverse the neurobiological and psychopathologic consequences of early life stress in humans. Thus, a recent study found that maltreated preschool children who were placed in an Early Intervention Foster Care program, which uses the foster-care setting for therapeutic intervention promoting positive parenting strategies, showed improved behavioral adjustment and overall decreases in salivary cortisol levels compared with children in normal foster care (Fisher et al 2000).

\section{Conclusion}

An unacceptably large number of children in our society are subjected to early adverse experiences, exposing these children to an increased risk for the development of depression or anxiety disorders, as well as other disorders, that may persist throughout adulthood. We have summarized findings from preclinical and clinical studies suggesting that early life stress induces long-lived hyperactivity and sensitization of CNS CRF and other neurotransmitter systems, resulting in enhanced endocrine, autonomic, and behavioral stress responsiveness. With repeated exposure to life stress, this vulnerability may result in symptoms of depression and anxiety disorders, as well as in other physiologic abnormalities frequently observed in adult survivors of abuse. Researchers have now begun to identify factors that moderate or reverse the effects of early life stress on neurobiological systems.

Most preclinical studies have examined the long-term impact of early life stress on brain development in adult animals, whereas a limited number of studies have evaluated the impact of early experiences in developing animals; however, neurobiological findings in children with early life stress differ in several aspects from findings in adults. There are also differences in the neurobiology of early-onset and adulthood depression, and early life stress appears to be a crucial factor in explaining these differences. Thus, preclinical studies focusing on developmental aspects of the effects of early life stress are urgently needed. These studies may help to understand time patterns in the development of neurobiological changes in relation to early life stress, to identify critical developmental periods sensitive to the effects of stress or intervention, and to help elucidate the mechanisms of early-onset depression.

It should be noted, however, that it is generally difficult to infer from animal studies on the effects of early life stress on human development. First, the length of periods of plasticity in various brain regions differs between rats and humans. Second, there are immanent difficulties in modeling typical stressful experiences of human infants or children in animal paradigms: maternal separation and VFD may best parallel instances of neglect of human children, whereas the human experiences of sexual or physical abuse include a commission, which may have differential neurobiological effects (Glaser 2000). Moreover, human early life stress is characterized by great variety with respect to age at onset, severity, frequency, and chronicity of the stressor, and additional environmental variations, such as the general family environment and the availability of coping resources, which contribute to the effects of the stress in humans. Fourth, different research methods to assess neurobiological systems in animals and humans complicate the direct comparison of findings.

Therefore, more studies in humans exposed to early life stress are needed. These studies will have to meet the challenge to identify differential immediate and long-term effects of great varieties of early life stress experienced at 
different developmental stages. Although difficult to realize, it will be indispensable to conduct longitudinal clinical studies, which will enhance our understanding of the critical developmental phases that are particularly sensitive to the effects of stress as well as pharmacologic or social buffering and that will provide unequivocal knowledge on a causal relationship between early life stress and the development of pathology in humans. The development of new techniques allowing for the assessment of central neurotransmitter and receptor changes, including CRF receptors, will considerably advance this clinical research and will increase the comparability of clinical and preclinical findings.

Future studies should further elucidate the role of predisposing factors in the manifestation of a vulnerable phenotype as a consequence of early life stress. For example, there may be genetic vulnerability to the neurobiological effects of early life stress. Thus, twin studies are needed for the prediction of neurobiological stress responsiveness as a function of genes, early life stress, and ongoing stress, among other factors. Although national epidemiologic studies suggest a similar incidence of childhood abuse in girls and boys, the role of gender in the development of neurobiological alterations after early life stress is a neglected area of research. And although the prevalence of early-onset depression is similar in girls and boys, adult women more often develop depression than men (Martin et al 2000). Gender differences in children's and adolescents' adaptation to sexual abuse have been reported (Feiring et al 1999), as well as differences in HPA axis reactivity in male and female healthy subjects and depressed adolescents (Dorn et al 1996; Kirschbaum et al 1999). Thus, future preclinical and clinical studies should evaluate the interaction between stress and gender in inducing neurobiological vulnerability to depression and anxiety.

Taken together, a pivotal role of early environmental variation in the development of long-term (mal)adaptations to stress has been documented in an impressive series of studies. The current database suggests that early adverse experiences should be addressed in the clinical care of children, adolescents, and adults with psychiatric disorders, a need that is often unmet in clinical practice.

Supported by The Conte Center for the Neurobiology of Mental Disorders and NIH MH Grant No. 42088.

Aspects of this work were presented at the conference, "The Unmet Needs in Diagnosis and Treatment of Mood Disorders in Children and Adolescents," October 17-18, 2000, in Washington DC. The conference was sponsored by the National Depressive and Manic-Depressive Association through unrestricted educational grants provided by Abbott Laboratories, AstraZeneca, Bristol-Myers Squibb Company, Forest Laboratories Inc., Glaxo Wellcome Inc., The Henry Foundation, Janssen Pharmaceutica, Eli Lilly and Company, Merck \& Co., National Institute of Mental Health, Pfizer Inc., Pharmacia, SmithKline Beecham, Solvay Pharmaceuticals Inc., and Wyeth-Ayerst Laboratories.

\section{References}

Agid O, Kohn Y, Lerer B (2000): Environmental stress and psychiatric illness. Biomed Pharmacother 54:135-141.

Agid O, Shapira B, Zislin J, Ritsner M, Hanin B, Murad H, et al (1999): Environment and vulnerability to major psychiatric illness: A case control study of early parental loss in major depression, bipolar disorder and schizophrenia. Mol Psychiatry 4:163-172.

Arborelius L, Owens MJ, Plotsky PM, Nemeroff CB (1999): CRF, depression and anxiety. J Endocrinol 160:1-12.

Arborelius L, Plotsky PM, Nemeroff CB, Owens MJ (2000): Increased 5-HT cell firing responsiveness to citalopram in adult rats previously subjected to maternal separation Soc Neurosci Abstr 26:867:17.

Baker DG, West SA, Nicholson WE, Ekhator NN, Kasckow JW, Hill KK, et al (1999): Serial CSF corticotropin-releasing hormone levels and adrenocortical activity in combat veterans with posttraumatic stress disorder. Am J Psychiatry 156:585588.

Bánki CM, Karmaksi L, Bissette G, Nemeroff CB (1992): Cerebrospinal fluid neuropeptides in mood disorder and dementia. J Affect Dis 25:39-46.

Birmaher B, Dahl RE, Perel J, Williamson DE, Nelson B, Stull $S$, et al (1996): Corticotropin-releasing hormone challenge in prepubertal major depression. Biol Psychiatry 39:267-277.

Brady LS, Gold P, Herkenham M, Lynn A, Whitfield HJ (1992): The antidepressants fluoxetine, idazoxan, and phenelzine alter corticotropin-releasing hormone and and tyrosine hydroxylase mRNA levels in rat brain: Therapeutic implications. Brain Res 572:117-125.

Brady LS, Whitfield HJ, Fox RJ, Gold PW, Herkenham M (1991): Long-term antidepressant administration alters corticotropin-releasing hormone, tyrosine hydroxylase, and mineralocorticoid receptor gene expression in rat brain. Therapeutic implications. J Clin Invest 87:831-837.

Breier A, Kelsoe JR Jr, Kirwin PD, Beller SA, Wolkowitz OM, Pickar D (1988): Early parental loss and development of adult psychopathology. Arch Gen Psychiatry 45:987-993.

Bremner JD, Innis RB, Southwick SM, Staib L, Zoghbi S, Charney DS (2000a): Decreased benzodiazepine receptor binding in prefrontal cortex in combat-related posttraumatic stress disorder. Am J Psychiatry 157:1120-1126.

Bremner JD, Innis RB, White T, Fujita M, Silbersweig D, Goddard AW, et al (2000b): SPECT [I-123]iomazenil measurement of the benzodiazepine receptor in panic disorder Biol Psychiatry 47:96-106.

Bremner JD, Narayan M, Anderson ER, Staib LH, Miller HL, Charney DS (2000c): Hippocampal volume reduction in major depression. Am J Psychiatry 157:115-118.

Bremner JD, Randall P, Scott TM, Bronen RA, Seibyl JP, Southwick SM, et al (1995): Magnetic resonance imagingbased measurement of hippocampal volume in patients with combat-related posttraumatic stress disorder. Am J Psychiatry 152:973-981.

Bremner JD, Randall P, Vermetten E, Staib L, Bronen RA, Mazure C, et al (1997): Magnetic resonance imaging-based measurement of hippocampal volume in posttraumatic stress disorder related to childhood physical and sexual abuse-a preliminary report. Biol Psychiatry 41:23-32. 
Butler PD, Weiss JM, Stout JC, Nemeroff CB (1990): Corticotropin-releasing factor produces fear-enhancing and behavioral activating effects following infusion into the locus coeruleus. J Neurosci 10:176-183.

Caldji C, Francis D, Sharma S, Plotsky PM, Meaney MJ (2000): The effects of early rearing environment on the development of GABAA and central benzodiazepine receptor levels and novelty-induced fearfulness in the rat. Neuropsychopharmacology 22:219-229.

Caldji C, Tannenbaum B, Sharma S, Francis D, Plotsky PM, Meaney MJ (1998): Maternal care during infancy regulates the development of neural systems mediating the expression of fearfulness in the rat. Proc Natl Acad Sci U S A 95:53355340

Carlson M, Earls F (1997): Psychological and neuroendocrinological sequelae of early social deprivation in institutionalized children in Romania. Ann N Y Acad Sci 807:419-428:

Chappell PB, Smith MA, Kilts CD, Bissette G, Ritchie JC, Andersen C, et al (1986): Alterations in corticotropin-releasing factor-like immunoreactivity in discrete barin regions after acute and chronic stress. J Neurosci 6:2908-2914.

Cokkinides VE, Coker AL, Sanderson M, Addy C, Bethea L (1999): Physical violence during pregnancy: Maternal complications and birth outcomes. Obstet Gynecol 93:661-666.

Coplan JD, Andrews MW, Rosenblum LA, Owens MJ, Friedman S, Gorman JM, et al (1996): Persistent elevations of cerebrospinal fluid concentrations of corticotropinreleasing factor in adult nonhuman primates exposed to early-life stressors: Implications for the pathophysiology of mood and anxiety disorders. Proc Natl Acad Sci U S A 93:1619-1623.

Coplan JD, Smith EL, Trost RC, Scharf BA, Altemus M, Bjornson L, et al (2000): Growth hormone response to clonidine in adversely reared young adult primates: Relationship to serial cerebrospinal fluid corticotropin-releasing factor concentrations. Psychiatry Res 95:93-102.

Cratty MS, Ward HE, Johnson EA, Azzaro AJ, Birkle DL (1995): Prenatal stress increases corticotropin-releasing factor (CRF) content and release in rat amygdala minces. Brain Res 675:297-302.

Davidson RJ, Putnam KM, Larson CL (2000): Dysfunction in the neural circuitry of emotion regulation-a possible prelude to violence. Science 289:591-594.

De Bellis MD, Baum AS, Birmaher B, Keshavan MS, Eccard CH, Boring AM, et al (1999a): Developmental traumatology. Part I: Biological stress systems. Biol Psychiatry 45:12591270.

De Bellis MD, Chrousos GP, Dorn LD, Burke L, Helmers K, Kling MA, et al (1994): Hypothalamic pituitary adrenal dysregulation in sexually abused girls. J Clin Endocrinol Metabol 78:249-255.

De Bellis MD, Gold P, Geracioti TD, Listwak SJ, Kling MA (1993): Association of fluoxetine treatment with reductions in CSF concentrations of corticotropin-releasing hormone and arginine vasopression in patients with major depression. Am J Psychiatry 150:656-657.

De Bellis MD, Keshavan MS, Clark DB, et al (1999b): A.E. Bennett Research Award. Developmental traumatology. Part II: Brain development. Biol Psychiatry 45:1271-1284.

De Bellis MD, Keshavan MS, Spencer S, Hall J (2000): N-
Acetylaspartate concentration in the anterior cingulate of maltreated children and adolescents with PTSD. Am J Psychiatry 157:1175-1177.

De Bellis MD, Lefter L, Trickett PK, et al (1997): Urinary catecholamine excretion in sexually abused girls. J Am Acad Child Adolesc Psychiatry 33:320-327.

Dent GW, Okimoto DK, Smith MA, Levine S (2000): Stressinduced alterations in corticotropin-releasing hormone and vasopressin gene expression in the paraventricular nucleus during ontogeny. Neuroendocrinology 71:333-342.

Dorn LD, Burgess ES, Susman EJ, von Eye A, De Bellis MD, Gold PW, et al (1996): Response to oCRH in depressed and nondepressed adolescents: Does gender make a difference? J Am Acad Child Adolesc Psychiatry 35:764-773.

Drevets WC (1999): Prefrontal cortical-amygdalar metabolism in major depression. Ann N Y Acad Sci 877:614-637.

Duman RS, Charney DS (1999): Cell atrophy in major depression. Biol Psychiatry 45:1083-1084.

Dunn AJ, Berridge CW (1990): Physiological and behavioral responses to corticotropin-releasing factor administration: Is CRF a mediator of anxiety or stress responses? Brain Res 15:71-100.

Fahlke C, Lorenz JG, Long J, Champoux M, Suomi SJ, Higley JD (2000): Rearing experiences and stress-induced plasma cortisol as early risk factors for excessive alcohol consumption in nonhuman primates. Alcohol Clin Exp Res 24:644650.

Famularo R, Kinscherff R, Fenton T (1992): Psychiatric diagnoses of maltreated children: Preliminary findings. J Am Acad Child Adolesc Psychiatry 31:863-867.

Feiring C, Taska L, Lewis M (1999): Age and gender differences in children's and adolescents' adaptation to sexual abuse. Child Abuse Negl 23:115-128.

Feldman S, Weidenfeld J (1995): Neural mechanisms involved in the corticosteroid feedback effects on the hypothalamo-pituitary-adrenocortical axis. Prog Neurobiol 45: 129-141.

Felitti VJ, Anda RF, Nordenberg D, Williamson DF, Spitz AM, Edwards V, et al (1998): Relationship of childhood abuse and household dysfunction to many of the leading causes of death in adults. The Adverse Childhood Experiences (ACE) Study. Am J Prev Med 14:245-258.

Fisher PA, Gunnar MR, Chamberlain P, Reid JB (2000): Preventive intervention for maltreated preschool children: Impact on children's behavior, neuroendocrine activity, and foster parent functioning. J Am Acad Child Adolesc Psychiatry 39:1356-1364.

Francis DD, Caldji C, Champagne F, Plotsky PM, Meaney MJ (1999): The role of corticotropin-releasing factor-norepinephrine systems in mediating the effects of early experience on the development of behavioral and endocrine responses to stress. Biol Psychiatry 46:1153-1166.

Gerra G, Zaimovic A, Zambelli U, Timpano M, Reali N, Bernasconi S, et al (2000): Neuroendocrine responses to psychological stress in adolescents with anxiety disorder. Neuropsychobiology 42:82-92.

Glaser D (2000): Child abuse and neglect and the brain-a review. J Child Psychol Psychiatry 41:97-116.

Goenjian AK, Yehuda R, Pynoos RS, et al (1996): Basal cortisol, 
dexamethasone suppression of cortisol, and MHPG in adolescents after the 1988 earthquake in Armenia. Am J Psychiatry 153:929-934:

Goodman SH, Gotlib IH (1999): Risk for psychopathology in the children of depressed mothers: A developmental model for understanding mechanisms of transmission. Psychol Rev 106:458-490.

Goodwin MM, Gazmararian JA, Johnson CH, Gilbert BC, Saltzman LE (2000): Pregnancy intendedness and physical abuse around the time of pregnancy: Findings from the pregnancy risk assessment monitoring system. Matern Child Health $J$ 4:85-92.

Gottman JM, Katz LF (1989): The effects of marital discord on young children's peer interaction and health. Dev Psychol 25:373-381.

Habib KE, Weld KP, Rice KC, Pushkas J, Champoux M, Listwak S, et al (2000): Oral administration of a corticotropin-releasing hormone receptor antagonist significantly attenuates behavioral, neuroendocrine, and autonomic responses to stress in primates. Proc Natl Acad Sci U S A 97:6079-6084

Hammen C, Davila J, Brown G, Ellicott A, Gitlin M (1992): Psychiatric history and stress: Predictors of severity of unipolar depression. J Abnorm Psychol 101:45-52.

Hart J, Gunnar M, Cicchetti D (1995): Salivary cortisol in maltreated children: Evidence of relations between neuroendocrine activity and social competence. Dev Psychopathology 7:11-26.

Hart J, Gunnar M, Cicchetti D (1996): Altered neuroendocrine activity in maltreated children related to symptoms of depression. Dev Psychopathology 8:201-214:

Hedin LW, Janson PO (2000): Domestic violence during pregnancy. The prevalence of physical injuries, substance use, abortions and miscarriages. Acta Obstet Gynecol Scand 79: $625-630$.

Heim C, Nemeroff CB (1999): The impact of early adverse experiences on brain systems involved in the pathophysiology of anxiety and affective disorders. Biol Psychiatry 46:15091522.

Heim C, Newport DJ, Heit S, Graham YP, Wilcox M, Bonsall R, Miller AH, Nemeroff CB (2000): Pituitary-adrenal and autonomic responses to stress in women after sexual and physical abuse in childhood. JAMA 284:592-597.

Heim C, Newport DJ, Bonsall R, Miller AH, Nemeroff CB (2001): Altered pituitary-adrenal axis responses to provocative challenge tests in adult survivors of childhood abuse: The role of comorbid depression. Am J Psychiatry 158:575-581.

Hidalgo RB, Davidson JR (2000): Selective serotonin reuptake inhibitors in post-traumatic stress disorder. J Psychopharmacol 14:70-76.

Hollander E, Kwon J, Weiller F, Cohen L, Stein DJ, et al (1998): Serotonergic function in social phobia: Comparison to normal control and obsessive-compulsive disorder subjects. Psychiatry Res 79:213-217.

Hulshoff PHE, Hoek HW, Susser E, Brown AS, Dingemans A, Schnack HG, et al (2000): Prenatal exposure to famine and brain morphology in schizophrenia. Am J Psychiatry 157: $1170-1172$.

Kaufman J (1991): Depressive disorders in maltreated children. J Am Acad Child Adolesc Psychiatry 30:257-265.
Kaufman J, Birmaher B, Perel J, Dahl RE, Moreci P, Nelson B, et al (1997): The corticotropin-releasing hormone challenge in depressed abused, depressed nonabused, an normal control children. Biol Psychiatry 42:669-679.

Kaufman J, Birmaher B, Perel J, Dahl RE, Stull S, Brent D, et al (1998): Serotonergic functioning in depressed abused children: Clinical and familial correlates. Biol Psychiatry 44:973981.

Kaufman J, Plotsky PM, Nemeroff CB, Charney D (2000): Effects of early adverse experiences on brain structure and function: Clinical Implications. Biol Psychiatry 48:778790.

Kaufman J, Ryan N (1999): The neurobiology of child and adolescent depression. In: Charney D, Nestler E, Bunny B, editors. The Neurobiological Foundation of Mental Illness. New York: Oxford University Press.

Kehne JH, Coverdale S, McCloskey TC, Hoffman DC, Cassella JV (2000): Effects of the CRF(1) receptor antagonist, CP 154,526 , in the separation-induced vocalization anxiolytic test in rat pups. Neuropharmacology 39:1357-1367.

Kendler KS, Bulik CM, Silberg J, Hettema JM, Myers J, Prescott CA (2000): Childhood sexual abuse and adult psychiatric and substance use disorders in women: An epidemiological and cotwin control analysis. Arch Gen Psychiatry 57:953-959.

Kendler KS, Neale MC, Kessler RC, Heath AC, Eaves LJ (1992): Childhood parental loss and adult psychopathology in women. A twin study perspective. Arch Gen Psychiatry 49:109-116.

Kendler KS, Kessler RC, Neale MC, Heath AC, Eaves LJ (1993): The prediction of major depression in women: Toward an integrated model. Am J Psychiatry 150:11391148.

Kirby LG, Rice KC, Valentino RJ (2000): Effects of corticotropin-releasing factor on neuronal activity in the serotonergic dorsal raphe nucleus. Neuropsychopharmacology 22:148162.

Kirschbaum C, Kudielka BM, Gaab J, Schommer NC, Hellhammer DH (1999): Impact of gender, menstrual cycle phase, and oral contraceptives on the activity of the hypothalamuspituitary-adrenal axis. Psychosom Med 61:154-162.

Ladd CO, Huot RL, Thrivikraman KV, Nemeroff CB, Meaney MJ, Plotsky PM (2000): Long-term behavioral and neuroendocrine adaptations to adverse early experience. Prog Brain Res 122:81-103.

Ladd CO, Owens MJ, Nemeroff CB (1996): Persistent changes in corticotropin-releasing factor neuronal systems induced by maternal deprivation. Endocrinology 137:1212-1218.

LeDoux JE (2000): Emotion circuits in the brain. Annu Rev Neurosci 23:155-184.

Lemieux AM, Coe CL (1995): Abuse-related posttraumatic stress disorder: Evidence for chronic neuroendocrine activation in women. Psychosom Med 57:105-115.

Liang KC, Lee EHY (1988): Intra-amygdala injections of corticotropin-releasing factor facilitate inhibitory avoidance learning and reduce exploratory behavior in rats. Psychopharmacology 96:232-236.

Liu D, Caldji C, Sharma S, Plotsky PM, Meaney MJ (2000a): Influence of neonatal rearing conditions on stress-induced 
adrenocorticotropin responses and norepinepherine release in the hypothalamic paraventricular nucleus. J Neuroendocrinol $12: 5-12$

Liu D, Diorio J, Day JC, Francis DD, Meaney MJ (2000b): Maternal care, hippocampal synaptogenesis and cognitive development in rats. Nat Neurosci 3:799-806.

Liu D, Diorio J, Tannenbaum B, Caldji C, Francis D, Freedman A, Sharma S, Pearson D, Plotsky PM, Meaney MJ (1997): Maternal care, hippocampal glucocorticoid receptors, and hypothalamic-pituitary-adrenal responses to stress. Science 277:1659-1662.

Luecken LJ (1998): Childhood attachment and loss experiences affect adult cardiovascular and cortisol function. Psychosom Med 60:765-772.

Maes M, Lin A, Bonaccorso S, van Hunsel F, Van Gastel A, Delmeire L, et al (1998): Increased 24-hour urinary cortisol excretion in patients with post-traumatic stress disorder and patients with major depression, but not in patients with fibromyalgia. Acta Psychiatr Scand 98:328-335.

Margolin G, Gordis EB (2000): The effects of family and community violence on children. Annu Rev Psychol 51:445479.

Mayberg HS, Liotti M, Brannan SK, McGinnis S, Mahurin RK, Jerabek PA, et al (1999): Reciprocal limbic-cortical function and negative mood: Converging PET findings in depression and normal sadness. Am J Psychiatry 156:675-682.

McCauley J, Kern DE, Kolodner K, Dill L, Schroeder AF, DeChant, et al (1997): Clinical characteristics of women with a history of childhood abuse. JAMA 277:1362-1368.

McEwen BS (1998): Protective and damaging effects of stress mediators. N Engl J Med 15:338:171-179.

McFarlane J, Parker B, Soeken K (1996): Abuse during pregnancy: Associations with maternal health and infant birth weight. Nurs Res 45:37-42.

McNeil TF, Cantor-Graae E, Weinberger DR (2000): Relationship of obstetric complications and differences in size of brain structures in monozygotic twin pairs discordant for schizophrenia. Am J Psychiatry 157:203-212.

Maccari S, Piazza PV, Kabbaj M, Barbazanges A, Simon H, Le Moal M (1995): Adoption reverses the long-term impairment in glucocorticoid feedback induced by prenatal stress. $\mathrm{J} \mathrm{Neu}$ rosci 15:110-116.

Martin A, Kaufman J, Charney D (2000): Pharmacotherapy of early-onset depression. Update and new directions. Child Adolesc Psychiatr Clin N Am 9:135-157.

Meaney MJ, Diorio J, Francis D, Weaver S, Yau J, Chapman K, et al (2000): Postnatal handling increases the expression of cAMP-inducible transcription factors in the rat hippocampus: The effects of thyroid hormones and serotonin. J Neurosci 20:3926-3395.

Michelson D, Galliven E, Hill L, Demitrack M, Chrousos G, Gold P (1997): Chronic imipramine is associated with diminished hypothalamic-pituitary-adrenal axis responsivity in healthy humans. J Clin Endocrinol Metab 82:2601-2606.

Mooy JM, de Vries H, Grootenhuis PA, Bouter LM, Heine RJ (2000): Major stressful life events in relation to prevalence of undetected type 2 diabetes: The Hoorn Study. Diabetes Care 23:197-201.

Mullen PE, Martin JL, Anderson JC, Romans SE, Herbison GP
(1996): The long-term impact of the physical, emotional, and sexual abuse of children: A community study. Child Abuse Negl 20:7-21.

Nemeroff CB (1999): The preeminent role of early untoward experience on vulnerability to major psychiatric disorders: The nature-nurture controversy revisited and soon to be resolved. Mol Psychiatry 4:106-108.

Newport DJ, Nemeroff CB (2000): Neurobiology of posttraumatic stress disorder. Curr Opin Neurobiol 10:211-218.

Norman RM, Malla AK (1994): A prospective study of daily stressors and symptomatology in schizophrenic patients. Soc Psychiatry Psychiatr Epidemiol 29:244-249.

Ogilvie KM, Rivier C (1997): Prenatal alcohol exposure results in hyperactivity of the hypothalamic-pituitary-adrenal axis of the offspring: Modulation by fostering at birth and postnatal handling. Alcohol Clin Exp Res 21:424-429.

Orr SP, Lasko NB, Metzger LJ, Berry NJ, Ahern CE, Pitman RK (1998): Psychophysiologic assessment of women with posttraumatic stress disorder resulting from childhood sexual abuse. J Consult Clin Psychol 66:906-913.

Owens MJ, Nemeroff CB (1991): Physiology and pharmacology of corticotropin-releasing factor. Pharmacol Rev 43:425473.

Owens MJ, Nemeroff CB (1994): Role of serotonin in the pathophysiology of depression: Focus on the serotonin transporter. Clin Chem 40:288-295.

Owens MJ, Plotsky PM, Nemeroff CB (1996): Peptides and affective disorders. In: SJ Watson, editor. Biology of Schizophrenia and Affective Disorders. Washington, DC: American Psychiatric Press, 259-293.

Pelcovitz D, Kaplan S, Goldenberg B, Mandel F, Lehane J, Guarrera J (1994): Post-traumatic stress disorder in physically abused adolescents. J Am Acad Child Adolesc Psychiatry 33:305-312.

Perry BD (1994): Neurobiological sequelea of childhood trauma: PTSD in children. In: Murburg M, editor. Catecholamine Function in Posttraumatic Stress Disorder: Emerging Concepts. Washington, DC: American Psychiatric Press, 173189.

Pich EM, Koob OF, Sattler SC, Menzaghi F, Heilig M, Heinrichs SC, et al (1993): Stress-induced release of corticotropinreleasing factor in the maygdala measured by in vivo microdialysis. Neurosci Abstr 18:535.

Pihoker C, Owens MJ, Kuhn CM, Schanberg SM, Nemeroff CB (1993): Maternal separation in neonatal rats elicits activation of the hypothalamic-pituitary-adrenocortical axis: A putative role for corticotropin-releasing factor. Psychoneuroendocrinology 18:485-493.

Pine DS, Coplan JD, Wasserman GA, Miller LS, Fried JE, Davies M, et al (1997): Neuroendocrine response to fenfluramine challenge in boys. Associations with aggressive behavior and adverse rearing. Arch Gen Psychiatry 54:839846.

Plotsky PM, Meaney MJ (1993): Early, postnatal experience alters hypothalamic corticotropin-releasing factor (CRF) mRNA, median eminence CRF content and stress-induced release in adult rats. Mol Brain Res 18:195-200.

Plotsky PM, Thrivikraman KV, Caldji C, Sharma S, Meaney MJ (in press): The effects of neonatal rearing environment on 
CRF mRNA and CRF receptor levels in adult rat brain. J Neurosci.

Price ML, Curtis AL, Kirby LG, Valentino RJ, Lucki I (1998): Effects of corticotropin-releasing factor on brain serotonergic activity. Neuropsychopharmacology 18:492-502.

Raadsheer, FC, Hoogendijk WJ, Stam FC, Tilders FJ, Swaab DF (1994): Increased numbers of corticotropin-releasing hormone expressing neurons in the hypothalamic paraventricular nucleus of depressed patients. Neuroendocrinology 60:436444.

Raadsheer FC, van Heerikhuize JJ, Lucassen PJ, Tilders FJ, Swaab DF (1995): Corticotropin-releasing hormone mRNA levels in the paraventricular nucleus of patients with Alzheimer's disease and depression. Am J Psychiatry 152:13721376.

Rajkowska G, Miguel-Hidalgo JJ, Wei J, Dilley G, Pittman SD, Meltzer HY, et al (1999): Morphometric evidence for neuronal and glial prefrontal cell pathology in major depression. Biol Psychiatry 45:1085-1098.

Rinne T, Westenberg HG, den Boer JA, van den Brink W (2000): Serotonergic blunting to meta-chlorophenylpiperazine (m-CPP) highly correlates with sustained childhood abuse in impulsive and autoaggressive female borderline patients. Biol Psychiatry 47:548-556.

Rogeness G, McClure E (1996): Development and neurotransmitter interactions. Dev Psychopathology 8:183-199.

Rosenblum LA, Coplan JD, Friedman S, Gorman JM, Andrews MW (1994): Adverse early experiences affect noradrenergic and serotonergic functioning in adult primates. Biol Psychiatry 35:221-227.

Ruppel RA, Kochanek PM, Adelson PD, Rose ME, Wisniewski SR, Bell MJ, et al (2001): Excitatory amino acid concentrations in ventricular cerebrospinal fluid after severe traumatic brain injury in infants and children: The role of child abuse. J Pediatr 138:18-25.

Sallee FR, Sethuraman G, Sine L, Liu H (2000): Yohimbine challenge in children with anxiety disorders. Am J Psychiatry 157:1236-1242.

Sanacora G, Mason GF, Rothman DL, Behar KL, Hyder F, Petroff OA, et al (1999): Reduced cortical gamma-aminobutyric acid levels in depressed patients determined by proton magnetic resonance spectroscopy. Arch Gen Psychiatry 56: 1043-1047.

Sanchez MM, Aguado F, Sanchez-Toscano F, Saphier D (1998): Neuroendocrine and immunocytochemical demonstrations of decreased hypothalamo-pituitary-adrenal axis responsiveness to restraint stress after long-term social isolation. Endocrinology 139:579-587.

Saunders BE, Villoponteaux LA, Lipovsky JA (1992): Child sexual assault as a risk factor for mental disorders among women: A community survey. J Interpers Violence 7:189204.

Sedlack AJ, BroadhurstDD (1996): Third National Incidence Study of Child Abuse and neglect. Washington, DC: U.S. Government Printing Office.

Sheline YI, Gado MH, Price JL (1998): Amygdala core nuclei volumes are decreased in recurrent major depression. Neuroreport 9:2023-2028.

Sheline YI, Wang PW, Gado MH, Csernansky JG, Vannier MW
(1996): Hippocampal atrophy in recurrent major depression. Proc Natl Acad Sci U S A 93:3908-3913.

Skelton KH, Nemeroff CB, Knight DL, Owens MJ (2000): Chronic administration of the triazolobenzodiazepine alprazolam produces opposite effects on corticotropin-releasing factor and urocortin neuronal systems. J Neurosci 20:12401248.

Stein DJ, Van Heerden B, Wessels CJ, Van Kradenburg J, Warwick J, Wasserman HJ (1999): Single photon emission computed tomography of the brain with Tc-99 m HMPAO during sumatriptan challenge in obsessive-compulsive disorder: Investigating the functional role of the serotonin autoreceptor. Prog Neuropsychopharmacol Biol Psychiatry 23: 1079-1099.

Stein MB, Walker JR, Anderson G, Hazen AL, Ross CA, Eldridge G, et al (1996): Childhood physical and sexual abuse in patients with anxiety disorders in a community sample. Am J Psychiatry 153:275-277.

Stein MB, Koverola C, Hanna C, Torchia MG, McClarty B (1997a): Hippocampal volume in women victimized by childhood sexual abuse. Psychol Med 27:951-959.

Stein MB, Yehuda R, Koverola C, Hanna C (1997b): Enhanced dexamethasone suppression of plasma cortisol in adult women traumatized by childhood sexual abuse. Biol Psychiatry 42:680-686.

Suomi SJ (1991): Early stress and adult emotional reactivity in rhesus monkeys. Ciba Found Symp 156:171-183.

Takahashi LK, Turner JG, Kalin NH (1992): Prenatal stress alters brain catecholaminergic activity and potentiates stressinduced behavior in adult rats. Brain Res 574:131-137.

Twisk JW, Snel J, Kemper HC, van Mechelen W (1999): Changes in daily hassles and life events and the relationship with coronary heart disease risk factors: A 2-year longitudinal study in 27-29-year-old males and females. J Psychosom Res $46: 229-240$

Valentino RJ, Foote SL, Aston-Jones G (1983): Corticotropinreleasing factor activates noradrenergic neurons of the locus coeruleus. Brain Res 270:363-367.

van der Kolk BA, Dreyfuss D, Michaels M, Shera D, Berkowitz R, Fisler R, et al (1994): Fluoxetine in posttraumatic stress disorder. J Clin Psychiatry 55:517-522.

van Oers HJ, DeKloet ER, Levine S (1998): Early versus late maternal deprivation differentially alters the endocrine and hypothalamic responses to stress. Brain Res 111:245-252.

Veith RC, Lewis N, Langohr JI, Murburg MM, Ashleigh EA, Castillo S, et al (1993): Effect of desipramine on cerebrospinal fluid concentrations of corticotropin-releasing factor in human subjects. Psychiatry Res 46:1-8.

Wallace DJ (1987): The role of stress and trauma in rheumatoid arthritis and systemic lupus erythematosus. Semin Arthritis Rheum 16:153-157.

Ward HE, Johnson EA, Salm AK, Birkle DL (2000): Effects of prenatal stress on defensive withdrawal behavior and corticotropin releasing factor systems in rat brain. Physiol Behav 70:359-366.

Weiss JM, Stout JC, Aaron M, Owens MJ, Nemeroff CB (1994): Experimental studies of anxiety and depression: Locus coeruleus and corticotropin-releasing factor. Brain Res Bull 35: $561-572$. 
Weller EB, Weller RA, Fristad MA, Bowes JM (1990): Dexamethasone suppression test and depressive symptoms in bereaved children: A preliminary report. J Neuropsychiatry Clin Neurosci 2:418-421.

Wong ML, Kling MA, Munson PJ, Listwak S, Licinio J, Prolo P, et al (2000): Pronounced and sustained central hypernoradrenergic function in major depression with melancholic features: Relation to hypercortisolism and corticotropin-releasing hormone. Proc Natl Acad Sci U S A 97:325-330.

Workel JO, Oitzl MS, Ledeboer A, DeKloet ER (1997): The Brown Norway rat displays enhanced stress-induced ACTH reactivity at day 18 after $24 \mathrm{~h}$ maternal deprivation at day 3 . Brain Res 103:199-203.

Yehuda R (2000): Biology of posttraumatic stress disorder. $J$ Clin Psychiatry 61:14-21.

Young EA, Lopez JF, Murphy-Weinberg V, Watson SJ, Akil H (2000): Hormonal evidence for altered responsiveness to social stress in major depression. Neuropsychopharmacology 23:411-418.

Zobel AW, Nickel T, Kunzel HE, Ackl N, Sonntag A, Ising M, et al (2000): Effects of the high-affinity corticotropin-releasing hormone receptor 1 antagonist R121919 in major depression: The first 20 patients treated. J Psychiatr Res 34:171-181. 